\title{
Temperature measurements and heat transfer in near-surface snow at the South Pole
}

\author{
Richard E. Brandt, Stephen G. Warren \\ Department of Atmospheric Sciences, University of Washington, Seattle, Washington 98195-1640, U.S.A.
}

\begin{abstract}
To study near-surface heat flow on the Antarctic ice sheet, snow temperatures were measured at South Pole Station to a depth of $3 \mathrm{~m}$ at $15 \mathrm{~min}$ intervals during most of 1992. Solar heating and water-vapor transport were negligible during the 6 month winter, as was inter-grain net thermal radiation, leaving conduction as the dominant heat-transport mechanism. The rate of temperature change at depth over 15 min intervals was smaller than that at the surface, by one order of magnitude at $20 \mathrm{~cm}$ depth and two orders of magnitude at $1 \mathrm{~m}$ depth. A finite-difference model, with conduction as the only heat-transfer mechanism and measured temperatures as the upper and lower boundary conditions, was applied to four sets of three thermistors each. The thermal conductivity was estimated as that which minimized the difference between modeled and measured 15 min changes in temperatures at the center thermistor. The thermal conductivity obtained at shallow depths (above $40 \mathrm{~cm}$ ) was lower than that given by existing parameterizations based on density, probably because the snow grains were freshly deposited, cold and poorly bonded. A model using only vertical conduction explains on average $87 \%$ of the observed $15 \mathrm{~min}$ temperature changes at less than $60 \mathrm{~cm}$ depth and $92 \%$ below $60 \mathrm{~cm}$. The difference between modeled and measured temperature changes decreased with depth. The discrepancies between model and observation correlated more strongly with the air-snow temperature difference than with the product of that difference with the square of the wind speed, suggesting that the residual errors are due more to non-vertical conduction and to sub-grid-scale variability of the conductivity than to windpumping. The residual heating rate not explained by the model of vertical conduction exceeds $0.2 \mathrm{~W} \mathrm{~m}^{3}$ only in the top $60 \mathrm{~cm}$ of the near-surface snow.
\end{abstract}

\section{INTRODUCTION}

Within an ice sheet, thermal energy is transferred primarily by conduction but other heat-transfer mechanisms can also contribute to varying degrees. Non-conductive processes can include wind-generated ventilation of the snowpack (windpumping), latent-heat transfer by water-vapor migration, convection of air in the pore spaces and solar radiative heating. These non-conductive mechanisms are limited to the uppermost few meters of the snow where there is permeability to air and water vapor, and penetration of solar radiation. Advection of heat with the movement of ice and generation of heat from basal sliding and ice deformation can also occur (Colbeck, 1993). Although the bulk of an ice sheet experiences only conductive-heat transfer, the possibility has been raised that non-conductive processes near the surface could cause shifts in ice-sheet temperatures (Clarke and others, 1987; Colbeck, 1993) and vertical mixing of air within the snowpack (Colbeck, 1989; Clarke and Waddington, 1991; Albert, 1995), as well as movement and deposition of atmospheric acrosols within the snowpack (Cunningham and Waddington, 1993; Harder and others, 1996). These effects could alter both ice-sheet temperatures and the geochemical record in ice cores, complicating reconstructions of paleoclimate (Waddington and Morse, 1994; Cuffey and others, 1995).

By comparing snow-temperature measurements taken over a period of 10 months at South Pole Station to a one- dimensional model of heat transfer by conduction only, we seek to determine how well simple vertical conduction can explain observed short-term temperature changes. We then examine the departures of the model as a function of depth in an attempt to detect evidence for an effect of windpumping on temperature profiles in snow on the Antarctic Plateau. During the entire 6 months between the March equinox and the September equinox, solar radiative heating of the snow is negligible at the South Pole and temperatures are so low $\left(<-40^{\circ} \mathrm{C}\right)$ that latent-heat transport is also insignificant. Heat transfer by inter-grain thermal radiative exchange is also small, as shown below. By comparing periods of strong and weak wind, we can therefore hope to identify the contributions of windpumping and conduction without the complications of radiative heating and water-vapor migration.

\section{SNOW TEMPERATURES AND RELATED MEASUREMENTS}

Temperatures were measured at a site in the "Clean Air Sector" upwind from the South Pole Station buildings, about $200 \mathrm{~m}$ from the nearest building (Clean Air Facility) and $300 \mathrm{~m}$ from the Dome (Station Center). Temperatures were recorded every $15 \mathrm{~min}$ from January to November 1992 at ten levels from the surface down to $3 \mathrm{~m}$. Type YSI 44033 thermistors were spaced at $20 \mathrm{~cm}$ intervals to $1 \mathrm{~m}$, then at 2 and $3 \mathrm{~m}$. They were installed horizontally approximately 
$20 \mathrm{~cm}$ into the corner of a $2 \mathrm{~m}$ pit. This was done by first inserting a $3 \mathrm{~mm}$ tube with an attached level into the pit wall and removing a small core, then inserting a thermistor with leads stiffened by white heatshrink tubing until the thermistor was pressed into the end of the hole. A small amount of snow was then tamped in from the pit to secure the leads. We estimate an accuracy of $\pm 6 \mathrm{~mm}$ for the burial depth of each thermistor, with errors caused by the insertion procedure and by the slight compaction during the 10 month observation period. The $3 \mathrm{~m}$ thermistor was buried into the bottom of the pit using the same method. Excavated snow was then finely chopped and the pit was back-filled with special care taken not to leave voids or to overcompress the snow. This back-filling procedure could have disrupted the snow texture near the thermistors and did cause some of the non-vertical heat fluxes that were detected near the surface during the first 2 months after installation, as shown below. Two thermistors were attached to a dowel $10 \mathrm{~cm}$ and $20 \mathrm{~cm}$ above the snow surface and switched on when they became buried by snowfall during the winter. An Omnidata Polycorder datalogger was used to provide a constant voltage source and to record the voltage drop across the thermistors in a voltage-divider circuit with reference resistors of $100 \mathrm{k} \Omega$ chosen to minimize self-heating. The datalogger was housed in a small insulated box buried in the snow about $7 \mathrm{~m}$ from the thermistor string. It was maintained at operating temperature by electrical heating with a power cord from an underground seismic vault about $30 \mathrm{~m}$ away in the direction of the station. Temperature disturbances caused by the thermistor installation were allowed to dissipate for 2 months before the temperature data were used to calculate average thermal conductivity as described below.

The thermistors were "interchangeable precision" thermistors, factory-calibrated at absolute temperature to $0.1 \mathrm{~K}$. We improved this calibration to $\pm 0.03 \mathrm{~K}$ by applying an offset correction during tests at $0^{\circ} \mathrm{C}$ in an ice-slush bath and at $-77.55^{\circ} \mathrm{C}$ in a bath of $\mathrm{CO}_{2}$ ice and ethanol. Selective radiative heating of thermistors during sunlit times was reduced to $0.2 \mathrm{~K}$ using aluminized mylar covers as described by Brandt and others (1991).

The datalogger was retrieved every $9 \mathrm{~d}$ for downloading the raw data. At this time, the snow accumulation and surface characteristics were documented. The downloading procedure introduced 31 data gaps of approximately $1.5 \mathrm{~h}$ each. Three longer data gaps of 61, 126 and $247 \mathrm{~h}$ occurred due to failure of the datalogger's battery or the heater during the months of June, August and November, respectively.

The six thermistors spaced at $20 \mathrm{~cm}$ intervals became more deeply buried as snow accumulated during the winter, as shown in Figure 1. Because of windpacking, the density of new snow is close to that of year-old snow. Therefore, the change in depth of burial was simply set equal to the accumulation. Error due to snow settlement is included in the error analysis below and is shown to be small compared to other errors. Nearly all the accumulation during the 10 month study period occurred during the polar night (April-September). As the snow ages, it slowly densifies due to further windpacking, metamorphism and compaction under pressure. Density profiles of the top $1 \mathrm{~m}$ of snow measured in January 1992 and the top $2 \mathrm{~m}$ in December 1992 are plotted in Figure 2. For both profiles, the density was measured twice at each depth in $5 \mathrm{~cm}$ increments using a Taylor-LaChapelle snow-density kit. The scatter due to the sampling of different layers in the snow at the same depth

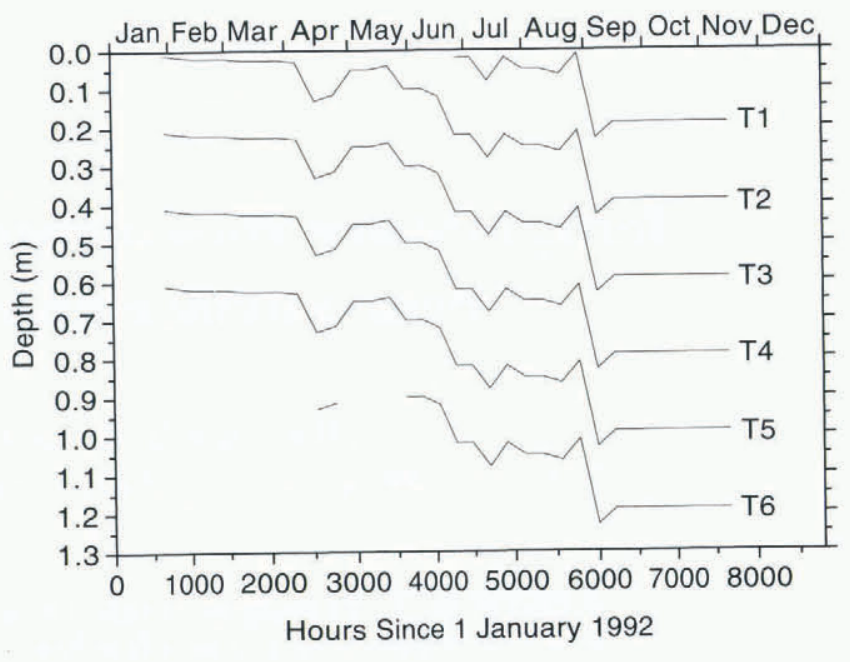

Fig. 1. Depth below the snow surface, as a function of time, for the six thermistors used in the conductivity analysis. Thermistor T1 was initially above the snow surface in fanuary; it was switched on when it became buried in late June. This figure assumes no differential compaction of the upper meter of snow over the 10 month experimental period.

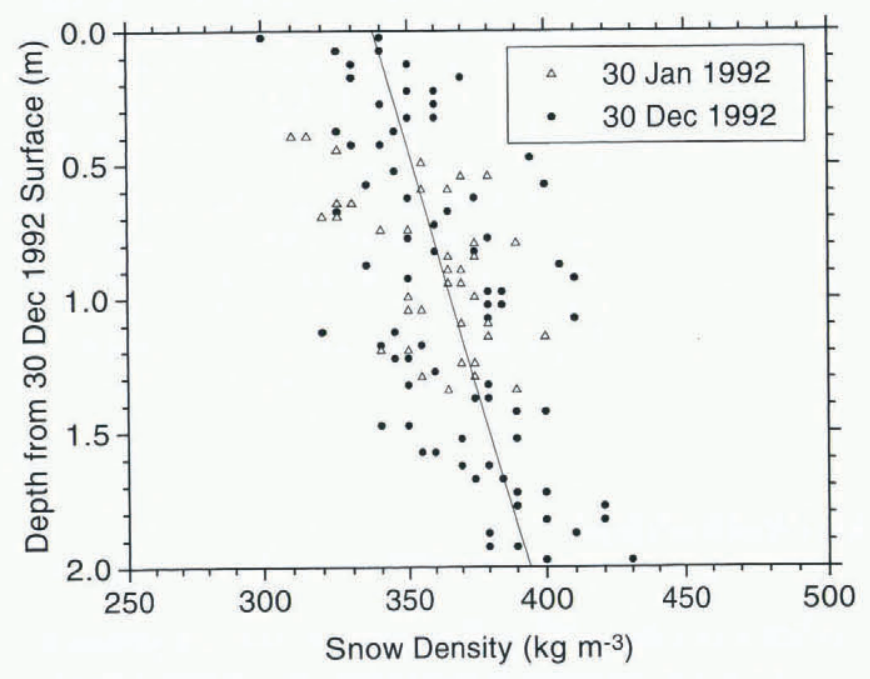

Fig. 2. Snow density at the thermistor site on 30 January and 30 December 1992 as a function of depth below the December surface. Linear regression is calculated assuming that all the scatter is due to density variation; that there is no error in depth measurement.

(because layers exhibit variable thickness on horizontal scales of less than $1 \mathrm{~m}$ ) greatly exceeds the systematic densification with time over the 10 months (estimated to be $3 \%$ ). For our model, we therefore use the linear fit to all the observed densities as a function of depth as shown in Figure 2 , varying in depth from the December surface but not varying in time. For the same reason, relative thermistor position is assumed not to vary with time and the error in thermistor position due to snow settling is combined with the error in initial thermistor placement for the error analysis below.

Wind speed at $10 \mathrm{~m}$ and air temperature at $2 \mathrm{~m}$ were recorded hourly by the South Pole Weather Office; they were measured on a mast $250 \mathrm{~m}$ from our snow-temperature experiment. Figure 3 shows the time series of air temperature, wind speed and surface pressure taken at South Pole Station and used in our analysis below. The lowest air temperatures occur throughout the 6 month night (April-September) when the snow surface approaches radiative 


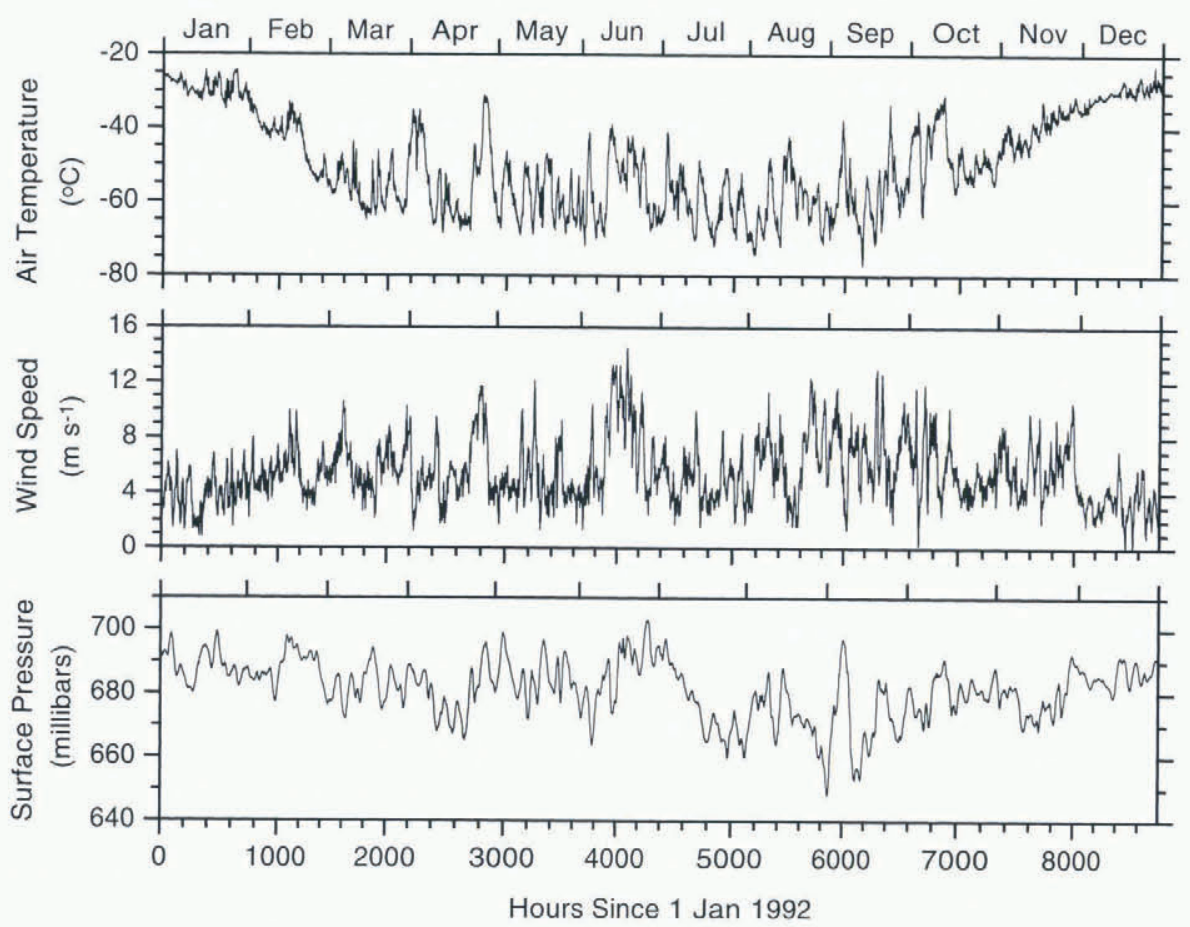

Fig. 3. Time series of hourly values of $2 \mathrm{~m}$ air temperature, $10 \mathrm{~m}$ wind speed and surface air pressure during 1992 at South Pole Station. Wind speed has been smoolhed for display by a five-point running-mean filler.

equilibrium with the sky. This "coreless winter" is normal at South Pole (Wexler, 1958; Schwerdtfeger, 1977). The warm intervals during these 6 months (Fig. 3) are usually times of strong wind and extensive cloud cover. The strong wind mixes warm air down from the top of the inversion layer (Schwerdtfeger, 1970) and the clouds emit longwave radiation downward more intensely than does the clear atmosphere. The strong winds that occur during the polar night are responsible for the growth of longitudinal snow dunes (sastrugi) during that season (Gow, 1965). Wind speeds in excess of about $7 \mathrm{~m} \mathrm{~s}^{-1}$ are required for significant drifting leading to the formation of sastrugi. Sastrugi of $10 \mathrm{~cm}$ height sometimes migrated past the observation site where they probably caused significant non-vertical heat conduction in the top $20 \mathrm{~cm}$, which will be discussed below.

Time series of temperatures measured by the six thermistors used in this study are plotted in Figure 4. Thermistor $\mathrm{T} 1$ was mounted on the dowel and became buried at the end of June. Thermistor T6 was switched on briefly in April and then permanently in mid-May when another thermistor (not used in this analysis) was switched off. The other four thermistors were operative for the entire sampling period except for the three data gaps that affected all thermistors. The filtering of high frequencies as thermistor T2

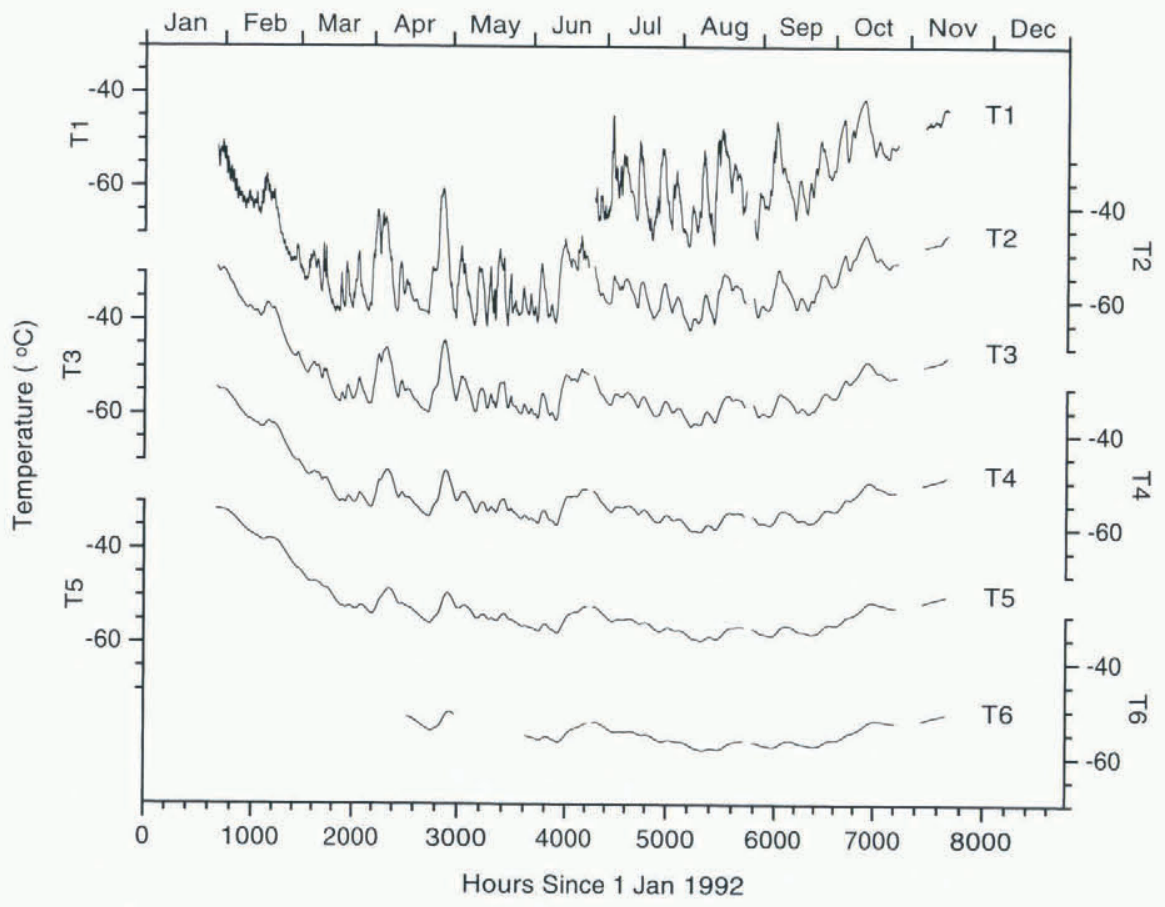

Fig. 4. Time series of sub-surface temperature measured by the six thermistors used in the conductivity analysis. 
became more deeply buried in March can be seen in Figure 4. Also, the temperature spike toward the end of April provides a good example of the attenuation and phase lag that occurs as an event moves deeper into the snow pack. Compared to thermistor T2 at $10 \mathrm{~cm}$ depth, T6 at $90 \mathrm{~cm}$ exhibits a peak only one-sixth as large and lagged by $80 \mathrm{~h}$. The attenuation with depth of surface-temperature changes is further apparent in Figure 5 where monthly average temperature profiles are shown. Figure 5 shows that at $3 \mathrm{~m}$ depth an annual cycle of amplitude $4 \mathrm{~K}$ remains, with a phase lag such that the summer maximum is reached in March and the winter minimum in October.

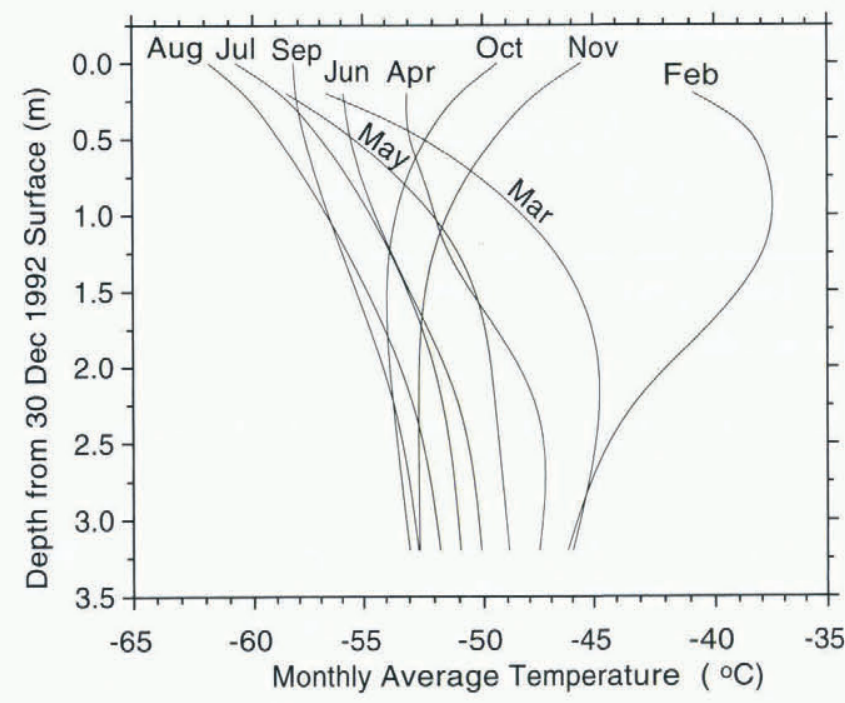

Fig. 5. Monthly average snow-temperature profiles for February through November 1992. The annual average $2 \mathrm{~m}$ air temperature is $-49.3^{\circ} \mathrm{C}$ (Schwerdtfeger, 1977); the snow temperature at $10 \mathrm{~m}$ depth is $-50.9^{\circ} \mathrm{C}$ (Dalrymple, 1966).
A $2 \mathrm{~d}$ segment of the $1 \mathrm{~m}$ temperature is shown as the points in Figure 6. This is the deepest of the thermistors used in the conductivity analysis below. Note that the recorded temperature varies by only $0.04 \mathrm{~K}$ over this $2 \mathrm{~d}$ period. To smooth the digital steps in the data seen in Figure 6, we have chosen to filter all our temperature records using a fivepoint running mean as shown by the continuous line in Figure 6. This filter was chosen for two reasons. First, the span of five points represents $1 \mathrm{~h}$; this matches the spacing of the meteorological observations which we correlate to our model output. Secondly, the ability of our model to predict temperature changes in the deepest levels was improved by increases of the averaging time up to $1 \mathrm{~h}$ but averaging over times longer than $1 \mathrm{~h}$ did not cause further improvement. Although the absolute accuracy of a temperature measurement is $\pm 0.03 \mathrm{~K}$, Figure 6 suggests that the changes of temperature with time at a single thermistor are accurate to about $\pm 0.002 \mathrm{~K}$. The five-point averaging reduces this error by the square-root of five, to about $\pm 0.001 \mathrm{~K}$.

During each $9 \mathrm{~d}$ period between downloads of the datalogger, about 860 temperatures were recorded at each thermistor, at $15 \mathrm{~min}$ intervals. After the $1 \mathrm{~h}$ smoothing, the change in temperature $\Delta T$ was computed for each thermistor for each $15 \mathrm{~min}$ interval. For each $9 \mathrm{~d}$ period, the largest of the 860 values of $\Delta T$, as well as the average $\Delta T$, is plotted in Figure 7. Although the air temperature can change by more than $1 \mathrm{~K}$ in $15 \mathrm{~min}$, below a depth of $20 \mathrm{~cm}$ the maximum 15 min temperature change throughout 1992 was only $0.1 \mathrm{~K}$, and at $1 \mathrm{~m}$ depth $0.007 \mathrm{~K}$. Aliasing (temperatures fluctuating on time-scales less than our 15 min sample rate) can occur for thermistors within $3 \mathrm{~mm}$ of the surface, but temperatures change more slowly at a depth of $20 \mathrm{~cm}$, and the smoothness of thermistor T3 (initial depth $20 \mathrm{~cm}$ ) in Figure 4 suggests that aliasing is not a problem at our $15 \mathrm{~min}$ sampling interval except when the topmost thermistor is just below the surface. As will be shown below in Figure

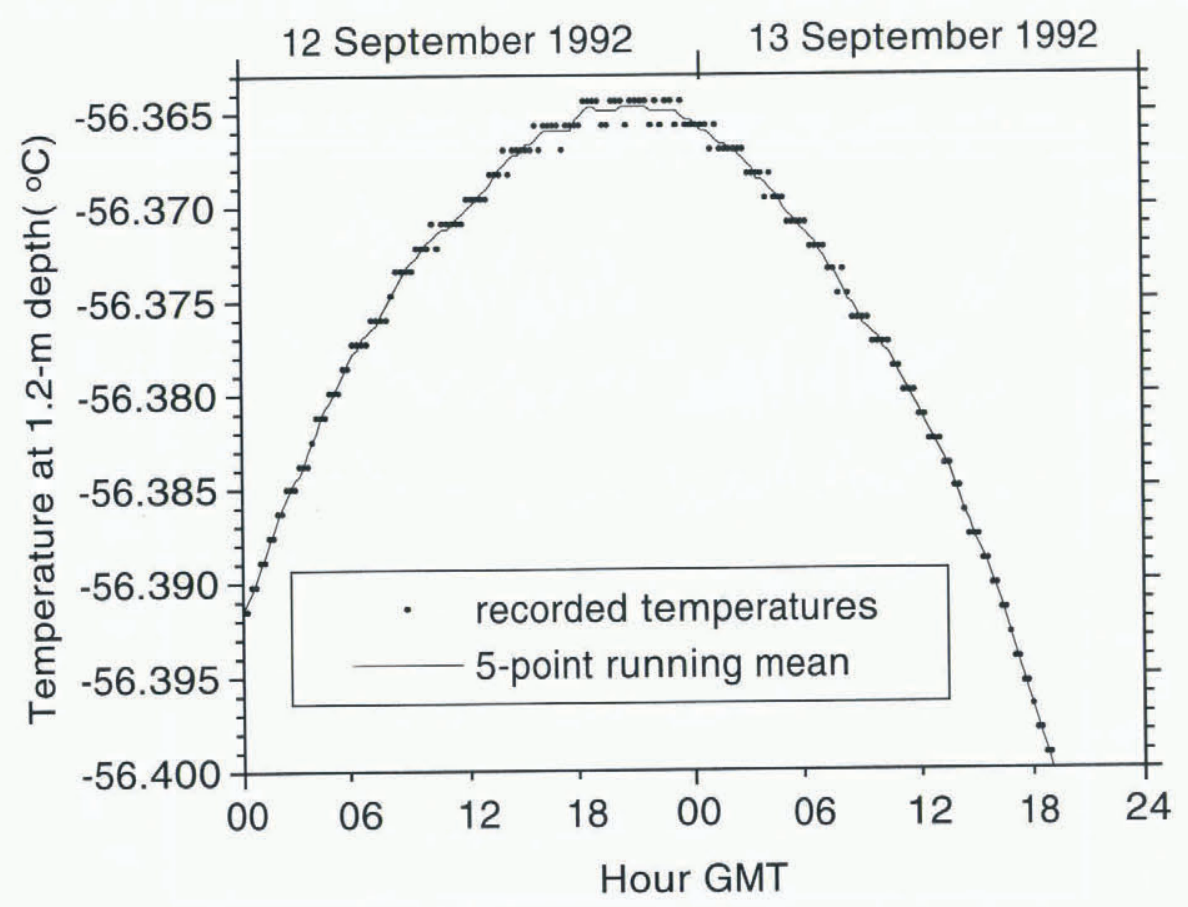

Fig. 6. Time series of temperature recorded at $1.2 \mathrm{~m}$ depth by thermistor $T 6$ over a $2 \mathrm{~d}$ period in September. The vertical axis spans a temperature range of $0.04 \mathrm{~K}$. The points are individual measurements at 15 min intervals. A five-point running mean is shown as the continuous line. 


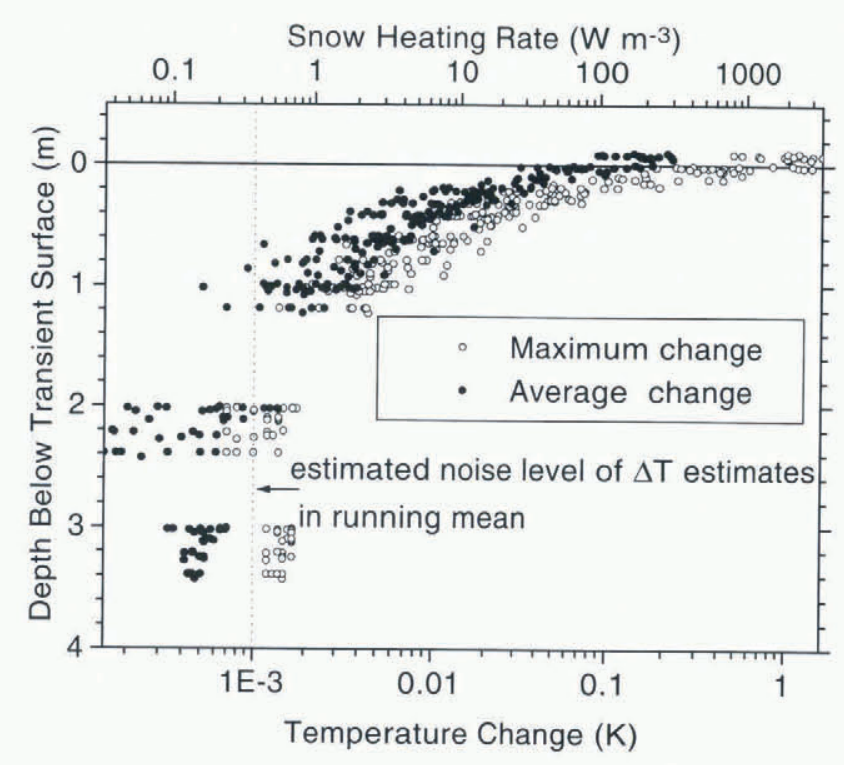

Fig. 7. Average 15 min temperature change $\Delta T$, and maximum 15 min temperature change, for each thermistor for each 9 d data-collection period, plotted at the depth where the thermistor was located during that particular $9 \mathrm{~d}$ period. About 860 values of $\Delta T$ (after the Ih smoothing) contribute to each point plotted here. The temperature change is converted to a heating rate (upper horizontal axis) using the density of snow and heat capacity of ice. The points above the snow surface are air temperatures measured by one of the thermistors before it was buried; only the temperature scale (not the heating-rate scale) applies to these points.

8a, an air-temperature oscillation with a period of $30 \mathrm{~min}$ is attenuated by a factor of about $10^{5}$ at $20 \mathrm{~cm}$ depth. Figure 7 shows that, at depths of $2 \mathrm{~m}$ and $3 \mathrm{~m}$, the $15 \mathrm{~min}$ temperature changes are mostly below the estimated noise level. In the conductivity analysis below, we therefore do not use the data from those deepest thermistors.

\section{EFFECTIVE THERMAL CONDUCTIVITY OF SNOW}

The effective thermal conductivity of snow $k_{\text {eff }}$ is defined by Equation (1):

$$
F=-k_{\text {eff }} \frac{\mathrm{d} T}{\mathrm{~d} z}
$$

where $F$ is the vertical heat flux $\left(\mathrm{Wm}^{-2}\right)$ and $\mathrm{d} T / \mathrm{d} z$ is the vertical temperature gradient. The conductivity $k_{\text {eff }}$ has been measured both in the laboratory and in situ in a wide range of experiments reviewed by Mellor (1977), Yen (1981) and most comprehensively by Sturm and others (in press). As Mellor pointed out, effective thermal conduction in snow includes heat transfer through the ice network, across air spaces or pores and by vapor diffusion through voids. It is important to note that windpumping, convection and radiative heating cannot be included in an effective thermal conductivity of snow, because these processes do not follow the Fourier heat-flow law and occur at different time-scales. Several attempts to parameterize heat conduction have expressed the effective conductivity as a function only of snow density. However, the variation among the experiments used to establish the parameterizations at a particular density exceeds a factor of 2 , with greater scatter at lower densities, indicating that conduction of heat in snow depends not only on density but also on snow texture (Mellor, 1977).
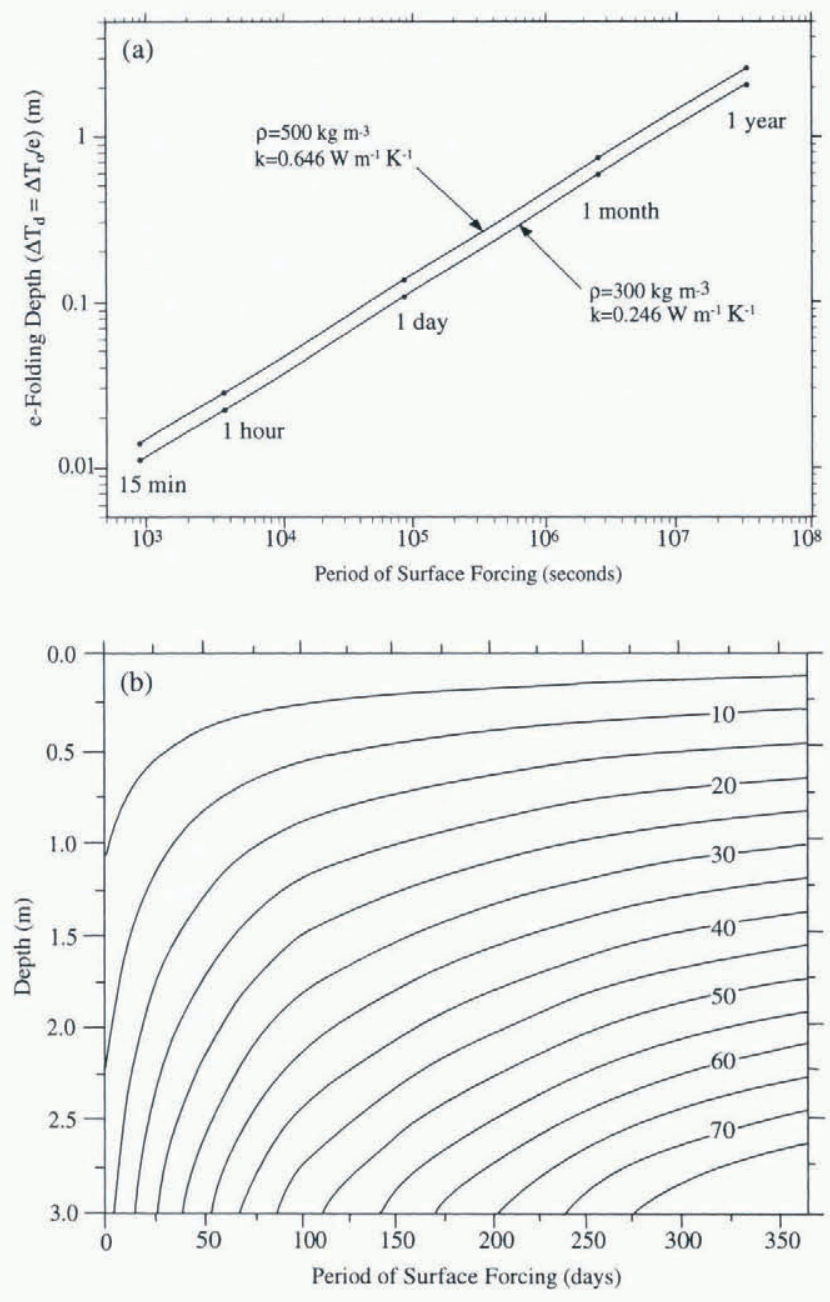

Fig. 8. (a) Theoretical e-folding depth of a periodic sinusoidal temperature variation imposed on a snow surface as a function of forcing period, for two snow densities, with conductivities from Anderson's (1976) parameterization. The e-folding depth dis defined such that $\Delta T_{d}=\Delta T_{0} / e$, where $\Delta T_{0}$ is the temperature amplitude at the surface and $\Delta T_{d}$ is the amplitude at depth d. (b) Theoretical phase lag in days as a function of depth and period of surface-temperature forcing for homogeneous snow with a density of $350 \mathrm{~kg} \mathrm{~m}^{-3}$ and a conductivity of $0.3 \mathrm{~W} \mathrm{~m}^{l} \mathrm{~K}^{\prime}$.

Adams and Sato (1993) developed a model for the thermal conductivity of dry snow idealized as spherical grains and used it to examine the effects of intergranular bonding and snow micro-structure. They concluded that, although the thermal conductivity of snow does depend strongly on density, it also depends on the intergranular bonding of snow grains which they quantified as the ratio of grain-contact radius to grain radius $\left(r_{\mathrm{c}} / r_{\mathrm{s}}\right)$. They also found that the temperature-dependence of snow conductivity depends on $r_{\mathrm{c}} / r_{\mathrm{s}}$. Well-bonded snow with $r_{\mathrm{c}} / r_{\mathrm{s}}=0.2$ behaves like pure ice in that it shows a decrease in conductivity with increasing temperature, indicating that the principal heat-transfer mechanism is through the ice network. However, the conductivity of poorly bonded snow, with $r_{\mathrm{c}} / r_{\mathrm{s}}=0.01$, increases with temperature above approximately $-30^{\circ} \mathrm{C}$. This is because the primary heat transfer in this case is by means of conduction in ice grains and in vapor-filled pores in series, and at these temperatures the latent-heat transfer by water vapor is significant and increases with temperature.

Several recent field measurements have demonstrated 
the influence of texture on snow conductivity. On the Filchner Ice Shelf, Lange (1985) found conductivity to vary by a factor of 5 for different snow samples at the same density, which he attributed to variation in grain structure. And for low-density depth hoar in Alaska, Sturm and Johnson (1992) found that differences in texture at constant density caused up to a seven-fold difference in conductivity. Our experiment, however, was not designed to measure the conductivity on a grain scale but rather on an engineering scale, because our thermistors were spaced $20 \mathrm{~cm}$ apart.

\section{ESTIMATING EFFECTIVE THERMAL CONDUCTIV- ITY FROM CHANGES IN SNOW TEMPERATURE}

Several methods have been developed to estimate the thermal-conductivity profile of an ice sheet from time series of temperature. An approach using harmonic analysis of snow temperatures to determine the attenuation and time lag of either the diurnal or annual temperature cycle was first used by Hjeltström (1889) and Abels (1892). For the case of snow on the Antarctic Plateau, this same method was pursued by Dalrymple and others (1966) and Weller and Schwerdtfeger (1977). However, this method does not account for snow accumulation and also assumes that non-conductive processes can be added to the effective thermal conductivity. The latter assumption fails in the case of windpumping where the conductive and advective terms in the heat-flow equation cannot be combined.

Lettau (1967) used snow-temperature measurements taken at South Pole Station over several individual $2 \mathrm{~d}$ periods to estimate the terms in the diffusion equation and to derive the thermal conductivity in the top $25 \mathrm{~cm}$ of the snowpack. He found values of conductivity $(0.05-0.25 \mathrm{~W}$ $\mathrm{m}^{-1} \mathrm{~K}^{-1}$ ) that were lower than expected for the snow density that was likely encountered $\left(300-400 \mathrm{~kg} \mathrm{~m}^{-3}\right)$. Bintanja and van den Brocke (1995) estimated the effective conductivity in snow $290 \mathrm{~km}$ inland from the coast of Antarctica near $75^{\circ} \mathrm{S}, 12^{\circ} \mathrm{W}$ by analyzing the change in phase and amplitude as the diurnal temperature cycle propagated downward. They obtained a conductivity of $0.25 \mathrm{~W} \mathrm{~m}^{-1} \mathrm{~K}^{-1}$ for a density of $400 \mathrm{~kg} \mathrm{~m}^{-3}$, which is lower than the average given by the parameterizations reviewed by Mellor (1977) and Yen (1981). As described below, we obtain results similar to Lettau (1967) and Bintanja and van den Broeke (1995) in the uppermost snow and will attempt an explanation.

Heat flow in horizontally homogeneous snow and ice can be approximated using a one-dimensional finite-difference model to explain measured temperatures (Brandt and Warren, 1993). This type of model is necessary if non-linear heat fluxes are to be included, such as volumetric heating by solar radiation. Trowbridge (1993) used a finite-difference model in an attempt to quantify the thermal effects of windpumping in the near-surface firn at Taylor Dome, Antarctica. His approach was to estimate the thermal diffusivity of the snow by analyzing the phase shift and amplitude attenuation of the diurnal cycle and also by using the parameterizations of Yen (1981) and Anderson (1976). He estimated the spectral radiative heating by the method of Brandt and Warren (1993) and compared his computed temperatures to measured temperatures to determine residual heating rates that might be associated with windpumping.

Our model follows the approach of Trowbridge (1993), by using a Crank-Nicholson finite-difference scheme to model conductive-heat flow. We then examine differences between modeled and measured temperature changes to estimate the contribution of non-conductive thermal fluxes. Our data set has the added benefit of 6 months without solar radiation and at temperatures below $-40^{\circ} \mathrm{C}$ where the contributions to the effective conductivity by latent-heat transfer and infrared-radiative transfer are both unimportant, as shown next.

\section{HEAT TRANSFER BY WATER VAPOR AND THERMAL RADIATION}

Yen (1981, equation (47)) estimated a thermal conductivity of $0.094 \mathrm{~W} \mathrm{~m}^{-1} \mathrm{~K}^{-1}$ caused by vapor diffusion in snow at 0 C. Although this could be significant for low-density snow, the same calculation gives only $0.003 \mathrm{~W} \mathrm{~m}^{-1} \mathrm{~K}^{-1}$ at $-40^{\circ} \mathrm{C}$ and $0.0002 \mathrm{~W} \mathrm{~m}^{-1} \mathrm{~K}^{1}$ at $-60^{\circ} \mathrm{C}$, because of the low saturation vapor pressure and correspondingly low gradient of vapor pressure, at low temperatures (saturation vapor pressure is $6.1 \mathrm{mbar}$ at $0^{\circ} \mathrm{C}$ but only $0.1 \mathrm{mbar}$ at $-40^{\circ} \mathrm{C}$ and 0.01 mbar at $-60^{\circ} \mathrm{C}$ ). The snow temperatures measured during our experiment were usually below $-40^{\circ} \mathrm{C}$, so latent-heat transport by vapor diffusion accounts for at most $1 \%$ of the heat flux.

We can also show that heat transfer by thermal radiation within the snowpack is small by the following argument. We model the snow grains as black bodies because the $e$-folding distance for absorption of thermal infrared radiation in ice is only 2-70 $\mu \mathrm{m}$ (Schaaf and Williams, 1973; Warren, 1984), whereas the snow-grain diameters are typically a few hundred $\mu \mathrm{m}$.

Using the Stefan-Boltzmann law, the thermal radiation energy flux exchanged between two neighboring blackbody snow grains $a$ and $b$ is

$$
F_{\text {rad }}=-4 \sigma T^{3}\left(T_{\mathrm{a}}-T_{\mathrm{b}}\right)
$$

where $\sigma$ is the Stefan-Boltzmann constant and $\left(T_{\mathrm{a}}-T_{\mathrm{b}}\right)$, the inter-grain temperature difference, is

$$
\left(T_{\mathrm{a}}-T_{\mathrm{b}}\right)=(\mathrm{d} T / \mathrm{d} z)_{\mathrm{gap}} \Delta z
$$

with $\Delta z$ the inter-grain spacing and $(\mathrm{d} T / \mathrm{d} z)_{\text {gap }}$ is the temperature gradient across the gap. This is larger than the bulk temperature gradient $\mathrm{d} T / \mathrm{d} z$ used in Equation (1), because air is much less conductive than ice. Because the porosity of South Polar snow is about $50 \%$ and assuming that each snow grain is nearly isothermal we therefore set $(\mathrm{d} T / \mathrm{d} z)_{\text {gap }} \approx 2 \mathrm{~d} T / \mathrm{d} z$. Then comparing $F_{\text {rad }}$ to the total heat flux $F$ from Equation (1), we obtain the ratio

$$
F_{\text {rad }} / F=8 \sigma T^{3} \Delta z / k_{\text {eff }} .
$$

We estimate the inter-grain spacing $\Delta z$ to be similar to the snow-grain diameter, which increases with depth but averages about $0.5 \mathrm{~mm}$ in the top meter of snow (Grenfell and others, 1994). Using $k_{\text {eff }}=0.3 \mathrm{~W} \mathrm{~m}^{-1} \mathrm{~K}$, we then find that the infrared heat flux is about $1 \%$ of the total in the summer $(T \approx 240 \mathrm{~K})$ and somewhat less in winter. 


\section{MODEL OF HEAT TRANSFER IN SNOW}

The model of simple vertical conduction starts with a onedimensional diffusion equation:

$$
\begin{aligned}
\rho(z) c(T) \frac{\partial T}{\partial t} & =\frac{\partial}{\partial z}\left(k_{\text {eff }} \frac{\partial T}{\partial z}\right) \\
& =\frac{\partial k_{\text {eff }}}{\partial z} \frac{\partial T}{\partial z}+k_{\text {eff }} \frac{\partial^{2} T}{\partial z^{2}} \approx k_{\text {eff }} \frac{\partial^{2} T}{\partial z^{2}}
\end{aligned}
$$

where $\rho(z)$ is the snow density, $c(T)$ is the heat capacity of ice, $k_{\text {eff }}$ is the effective thermal conductivity, $T$ is temperature, $t$ is time and $z$ is depth. We assume that $k_{\text {eff }}$ does not vary significantly within each $40 \mathrm{~cm}$ depth interval used in the model, which reduces the righthand side of Equation (5) to one term. This source of error is discussed in the analysis below. Equation (5) is approximated using the CrankNicholson finite-difference method (Press and others, 1992, equation 17.2.13):

$$
\begin{aligned}
\frac{T_{j}^{n+1}-T_{f}^{n}}{\Delta t} & =\frac{k_{\mathrm{eff}}}{2 \rho(z) c(T)} . \\
& {\left[\frac{T_{j+1}^{n+1}-2 T_{j}^{n+1}+T_{j-1}^{n+1}+T_{j+1}^{n}-2 T_{j}^{n}+T_{j-1}^{n}}{(\Delta z)^{2}}\right] }
\end{aligned}
$$

where $T_{j}^{n}$ is the temperature in level $j$ at time step $n$. The system of equations in this approximation forms a tridiagonal matrix which is efficient to compute. This method was chosen for its second-order accuracy and unconditional stability at any depth step for a given time step. All model runs used 57 depth steps of $\Delta z=7.02 \mathrm{~mm}$ each. We chose this number of depth steps by testing the model for the case of a sinusoidal periodic surface-temperature forcing whose solution can be determined analytically as described by Turcotte and Schubert (1982, p. 155). Comparing analytic and modeled temperatures driven by a surface forcing period of $30 \mathrm{~min}$ the shortest we can resolve at a $15 \mathrm{~min}$ sampling rate), our model showed no significant improvement using more than 57 levels. We also ran the model at different vertical resolutions to solve for conductivity during the $9 \mathrm{~d}$ period with the most rapidly fluctuating temperatures. The derived conductivity became insensitive to the number of levels when the number of levels reached 29, so our choice of 57 levels ensures adequate vertical resolution. An odd number of levels is chosen so that the center thermistor coincides with a model level.) This method differs from Lettau's (1967) and Zhang and Osterkamp's (1995) methods to solve Equation (5) which require a thermistor at each level or node. We do not have sufficient vertical resolution in our data set to use the type of finite-difference method they used. For the time step $\Delta t$ we used either $15 \mathrm{~min}$, the same as the original data, or $1 \mathrm{~h}$, the smoothing interval. The derived conductivities were insensitive to the choice of time step. For the figures shown in this paper, the model used a 15 min time step.

Although the air temperature can change significantly in less than $30 \mathrm{~min}$, such high-frequency temperature changes attenuate rapidly in the near-surface snow. The analytical $e$-folding depth for a wide range of forcing periods is shown in Figure 8a. Changes of temperature with periods less than $1 \mathrm{~h}$ are expected to dissipate within the top $5 \mathrm{~cm}$ of the snowpack. Likewise, the phase lag of thermal-wave propagation through the snowpack depends on the period of surface-temperature forcing, with longerperiod temperature changes moving more slowly through the snowpack as shown in Figure 8b. For the annual cycle, Figure $8 \mathrm{a}$ indicates an $e$-folding depth of $2 \mathrm{~m}$ and a phase lag at $3 \mathrm{~m}$ of $75 \mathrm{~d}$, consistent with the measurements shown in Figure 5.

Three thermistors are used to constrain each model run: one each for the upper and lower boundary conditions and an intermediate one to compare with a modeled center temperature. The residual temperature change $\epsilon(t)$ is the difference between the computed temperature change at the center of the modeled region and the measured temperature change there. With the thermistors spaced a fixed $20 \mathrm{~cm}$ apart, the regions modeled are $40 \mathrm{~cm}$ in vertical extent and thermal conductivity is assumed to be constant within a $40 \mathrm{~cm}$ region. This assumption is acceptable at our scale of interest, although an average conductivity over $40 \mathrm{~cm}$ does not address variation in effective conductivity at the grain scale or at the scale of variation in density. Given six thermistors with equal $20 \mathrm{~cm}$ spacing (Fig. 1), we can model four overlapping regions and determine a conductivity profile.

With no diurnal cycle at the South Pole and as our data do not cover a complete annual cycle, we are not able to use the harmonic methods described above to determine the effective thermal conductivity. Instead, for each of the 32 periods (approximately $200 \mathrm{~h}$ each) and for each of the four depth groups, we ran the model repeatedly with different specified conductivities to find the conductivity that minimized the r.m.s. difference $\epsilon_{\text {rms }}$ between measured and modeled temperature changes:

$$
\epsilon_{\mathrm{rms}}=\sqrt{\frac{\sum_{n=120}^{N}\left(\Delta T_{\mathrm{c}}{ }^{n}-\Delta T_{\mathrm{m}}{ }^{n}\right)^{2}}{N-120}}
$$

where $\Delta T_{\mathrm{c}}{ }^{n}$ is the computed and $\Delta T_{\mathrm{m}}{ }^{n}$ the measured change in center temperature at time step $n$ and $N$ is the total number of time steps. The least-squares norm was chosen because it determines the most probable value of $\epsilon$ assuming that the residuals are randomly distributed. The initial profile of temperature at the 57 levels for each model run was estimated by applying a cubic spline to the three measured temperatures. Computation of $\epsilon_{\text {rms }}$ was started at time step $n=120$, so as not to include initial transients in the model due to the interpolation of the initial temperature profile. By examining the error caused by this interpolation, in the case of a periodic surface forcing whose solution is known, we found that 120 time steps (30 model hours) was an adequate delay to avoid the transient effects of errors in the initial temperature profile. To minimize data "lost" by this initial delay, we calculated conductivity only for the 32 data-collection periods which contained the longest continuous data segments approximately 200 model hours each).

Examples of model runs are shown in Figure 9 for each of the four depth groups for the four data-collection periods (D6, D15, D20 and D31) with the lowest average wind speed. The top group has only two curves and the bottom group three; their thermistors were not all recording for some of the low-wind periods. Each curve displays a single minimum which is more clearly defined for periods in which there was more variation in temperature. These four datacollection periods had an average wind speed less than $2.5 \mathrm{~m} \mathrm{~s}^{-1}$ and a peak wind speed less than $5.1 \mathrm{~m} \mathrm{~s}^{-1}$. This is compared to an average wind speed of $6.0 \mathrm{~m} \mathrm{~s}{ }^{1}$ and a stan- 

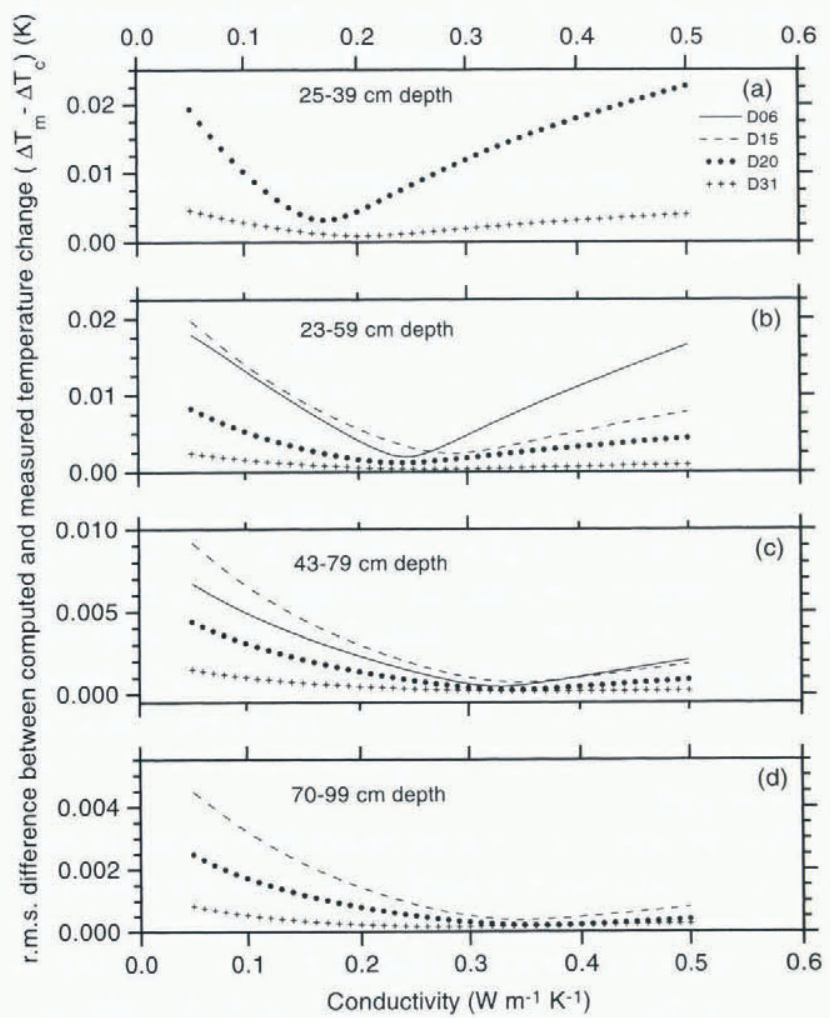

Fig. 9. Root-mean-square difference between computed and measured $15 \mathrm{~min}$ temperature changes $\left(\Delta T_{\mathrm{m}}-\Delta T_{\mathrm{c}}\right)$ (Equation (7)), using the pure-conduction model (Equation (6) ), as a function of the conductivity specified in the model, for the four $9 d$ data-collection periods of lowest wind speed (indicated by download-number D06, D15, D20, D31). The four frames are for four sets of three thermistors each, labeled by the range of depths occupied by the central thermistor of the set over the course of these four data-collection periods (Fig. I). Note that the vertical scale is expanded by a factor of 2 in (c) and a factor of 5 in (d) to display the much smaller temperature changes experienced by the deeper snow.

dard deviation of $2.6 \mathrm{~m} \mathrm{~s}^{-1}$ during the 8 month period when conductivities were calculated.

These low-wind periods were chosen to estimate conductivity when windpumping effects would be smallest. Our initial intention was to use low-wind periods to establish the conductivity for each thermistor group; however, the average conductivity of all the periods for each group differed by less than $0.01 \mathrm{~W} \mathrm{~m}^{-1} \mathrm{~K}^{-1}$ from the average of the low-wind periods.

The accuracy of the calculated conductivity is dependent on errors in the assumed density profile, the measured temperatures, the thermistor positions and the time of measurement. The standard error in the mean of the density measurements in Figure 2 over a $40 \mathrm{~cm}$ region is less than $5 \mathrm{~kg} \mathrm{~m}^{-3}$, or a relative error of $<1.5 \%$. This translates to an equal relative error in conductivity, because $\rho$ is proportional to $k_{\text {eff }}$ in Equation (5). Error due to the time of data acquisition is insignificant as the Polycorder's clock is accurate to better than $0.1 \mathrm{~s}$ in $15 \mathrm{~min}$. To estimate the contributions of errors in temperature and thermistor position, the model was run 500 times with an offset error introduced in each of the three temperatures and each of the three thermistor positions, from a random Gaussian distribution with standard deviations of $0.03 \mathrm{~K}$ for temperatures and $6 \mathrm{~mm}$ for thermistor positions. A $9 \%$ relative error in conductivity was the maximum estimated in the case of the deepest thermistors where temperatures are changing more slowly and conductivity is not as well constrained. Combined with the error due to density variation, the total uncertainty in $k_{\text {eff }}$ (for individual $9 \mathrm{~d}$ periods) is $10 \%$ at $60-100 \mathrm{~cm}$ depth and $8 \%$ at shallower depths, with errors in $\Delta z$ and $\Delta T$ contributing about equally.

For each depth group, the conductivity that minimized $\epsilon_{\mathrm{rms}}$ and its uncertainty is shown for each data-collection period in Figure 10. Horizontal lines indicate the average conductivity for groups B, C and D. A transient period in February is apparent in groups B and C, probably due to the disturbance of the thermal regime in the nearby backfilled snow pit, or to solar heating. Therefore, the average conductivity was computed beginning at sunset (21 March), 2 months after the thermistor installation, so that temperatures in the snow pit would have equilibrated to their surroundings and so that solar heating would be negligible. For group A, a least-squares linear fit, rather than an average, is shown; the motivation for this exception is discussed below. To obtain the error bars for Figure 10, we make a judgment about the accuracy to which $k_{\text {eff }}$ is determined in curves such as those of Figure 9. Curves with sharp minima indicate well-defined values of $k_{\text {eff }}$ We first compute the r.m.s.

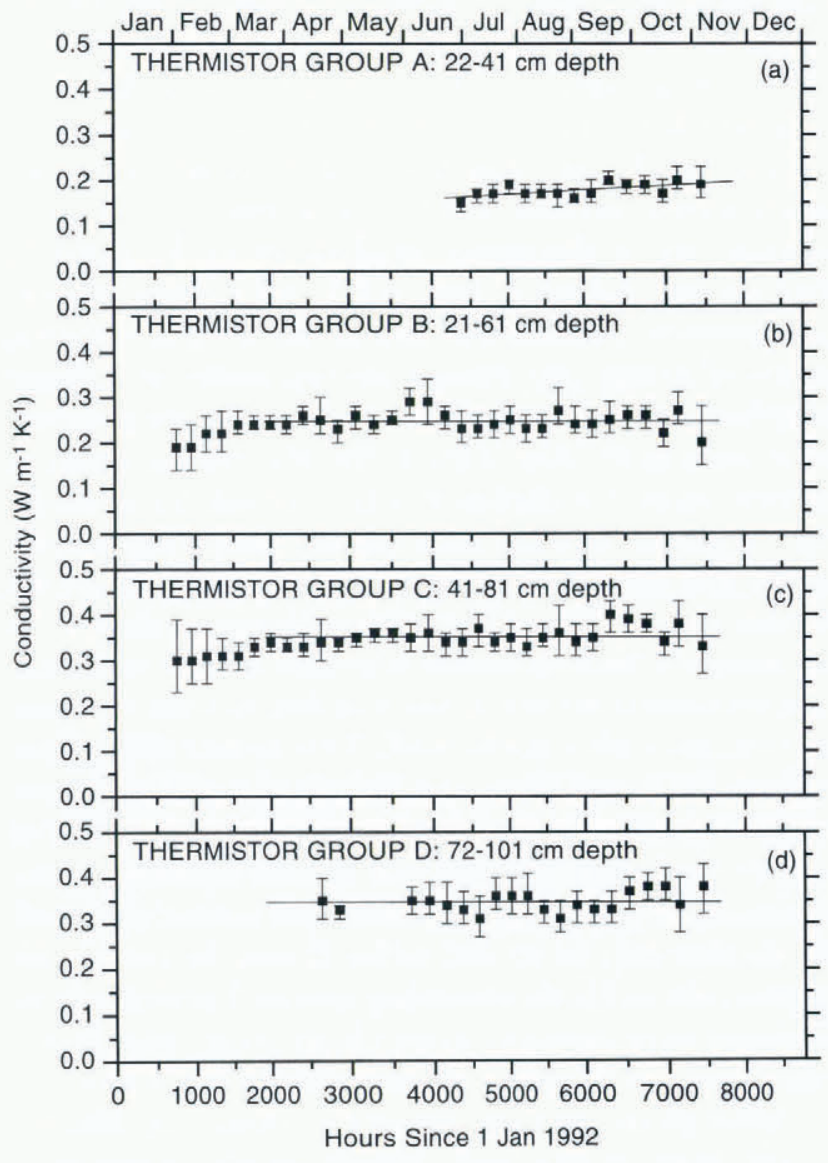

Fig. 10. Best-fit model conductivities for all periods for the four thermistor groups. Error bars indicate conductivities that gave $\pm 10 \%$ relative error in computed temperature changes, as explained in the text. The horizontal lines in $(b),(c)$ and (d) are averages over the experimental period, excluding the first 2 months (see text). The straight line in (a) is a leastsquares fit to the points. 
temperature change for a given thermistor for a $9 \mathrm{~d}$ datacollection period:

$$
\Delta T_{\mathrm{rms}} \equiv \sqrt{\frac{\sum_{n=120}^{N}\left(\Delta T_{\mathrm{m}}{ }^{n}\right)^{2}}{N-120}} .
$$

We then locate (e.g. on Figure 9) the values of $k_{\text {eff }}$ for which $\epsilon_{\mathrm{rms}}=0.1 \Delta T_{\mathrm{rms}}$, indicating $10 \%$ relative error, consistent with the uncertainty estimate above. These values of $k_{\text {eff }}$ define the top and bottom of the error bars in Figure 10. In general, the conductivity is less narrowly constrained for the deeper thermistors, because temperatures change more slowly at depth.

The four average conductivities from Figure 10 are plotted vs depth in Figure 11, along with the density-dependent parameterizations of Anderson (1976) and Yen (1981):

$$
\begin{aligned}
& k_{\text {And }}=0.021+2.5 \rho^{2} ; \\
& k_{\text {Yen }}=2.2362 \rho^{1.885}
\end{aligned}
$$

where $k$ is in $\mathrm{Wm}^{-1} \mathrm{~K}^{-1}$ and $\rho$ is density in $\mathrm{Mg} \mathrm{m}^{-3}$. Error bars in Figure 11 show the range of conductivities and depths for each thermistor group from the individual periods shown in Figure 10. The conductivities for the lower two thermistor groups are consistent with the Anderson (1976) and Yen (1981) parameterizations but the top two groups have significantly lower conductivities, although they still remain within the scatter of measurements used by Anderson and Yen to compute their parameterizations. The snow in which our low near-surface conductivities were measured fell mostly during the polar night and had never experienced high temperatures and solar radiation. Although an increase of bonding with time due to the snow grains' small radius of curvature (Kelvin effect) might still occur at low temperatures, this winter snowfall had probably not become well bonded, which could explain the low conductivities measured. This condition would correspond to a small value of $\left(r_{\mathrm{c}} / r_{\mathrm{s}}\right)$ in the Adams and Sato (1993) model.

The conductivity of group A increased slowly with time from June to October. This increase is probably typical as new snow ages. The parameterizations of Anderson (1976)

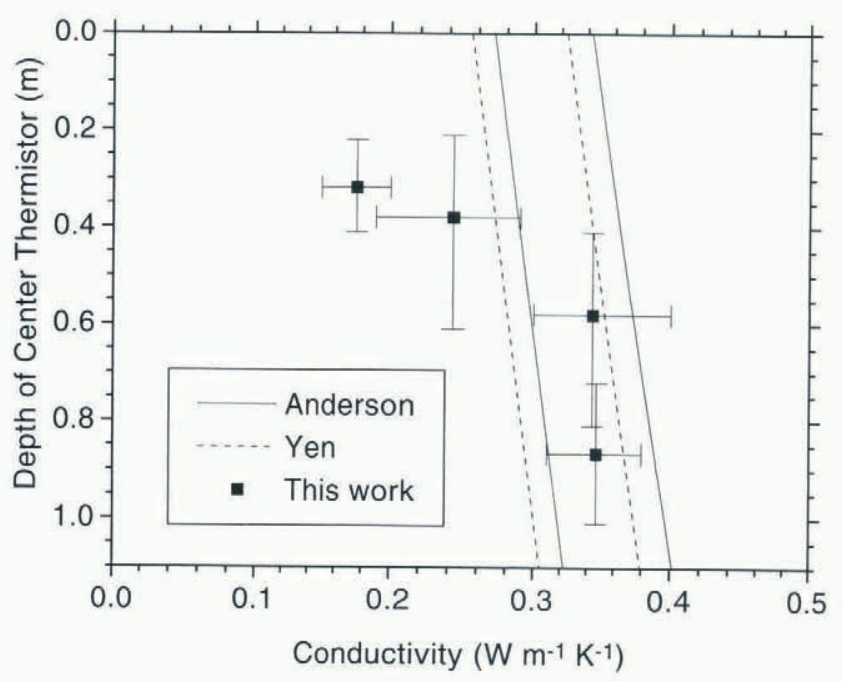

Fig. 11. Average conductivity of each thermistor group as a function of depth. Error bars indicate the range of modeled conductivity and range of depths of the center thermistor for all periods. Lines indicate parameterizations based on density (Equations (9) and (10)), using densities one standard deviation above and below the measured values shown in Figure 2. and Yen (1981) were based primarily on measurements of old snow; Figure 11 shows that the South Polar snow approaches agreement with the parameterizations as it ages. At $1 \mathrm{~m}$ depth, our conductivity also agrees with that inferred by Weller and Schwerdtfeger (1977) for the snow at Plateau Station. The accumulation rate at our experiment site is about $40 \mathrm{~cm}$ of snow per year, so thermistor group D represents snow that is 2-3 years old, whereas group A represents snow that is at most a few months old. (The annual accumulation at a distance of several kilometers away from South Pole Station is only $20 \mathrm{~cm}$ but the station itself disrupts surface winds and causes excess snow accumulation nearby.) The rate of growth of necks connecting grains probably is greatest during the warmest months, December and January, which have mean surface-air temperatures of $28^{\circ} \mathrm{C}$. The conductivity in the uppermost layer therefore probably increased more rapidly in the 3 months following the termination of this experiment than it did during the measured period June-October (Fig. 10a). As further qualitative evidence for increased grain bonding with depth, we note that snow shoveled near the surface appeared well packed but not cohesive, much like dry sand, whereas at the bottom of the $2 \mathrm{~m}$ pit the snow extracted by shoveling was in the form of well-bonded blocks.

Snow grain-size does normally increase with depth or age (LaChapelle, 1969). Grenfell and others (1994) measured snow grain-size at the South Pole by means of photomicrographs and found radii averaging $50 \mu \mathrm{m}$ at the surface, increasing to about $300 \mu \mathrm{m}$ at $50 \mathrm{~cm}$ depth. In addition to grain-size, snow texture is also important for the conductivity but has apparently not yet been studied in the surface snow of the Antarctic Plateau. A review of current knowledge involving the relationship between snow texture and heat transfer (Arons and Colbeck, 1995) has argued for more field observations of heat transfer in relation to the micro-structure of snow.

The curves in Figure 9 show that, although there is a single conductivity minimum for each period, there is still a residual error in the predicted temperature change $\left(\epsilon_{\mathrm{rms}}\right)$ at the best-fit conductivity and that $\epsilon_{\mathrm{rm}}$ is larger nearer the surface. The likely contributors to this residual temperaturechange error are model error due to the finite-difference approximation, temperature-measurement error, thermistorplacement error, non-vertical heat fluxes, variation in density and snow texture, which would cause $k_{\text {eff }}$ to vary at scales smaller than our thermistor spacing and non-conductive heat fluxes. We next convert $\epsilon_{\text {rms }}$ into a residual heating rate as a function of depth in order to set an upper limit to the thermal effect of non-conductive heat fluxes.

Rather than using the best-fit conductivities for each $9 \mathrm{~d}$ period shown in Figure 10, we use the average conductivity for each group (horizontal lines in Figure 10), except for the one closest to the surface (group A) for which we specify conductivity increasing linearly with time as indicated in Figure 10a. We believe there is no physical reason to explain the week-to-week variation in optimal conductivity shown in Figure 10 other than model and measurement error or non-conductive or non-vertical heat fluxes, except near the surface where the snow may be undergoing more rapid metamorphism. By using the average conductivity, our values of $\epsilon_{\mathrm{rms}}$ will be larger than the minima shown in Figure 9 and we will by default assign any true change in conductivity to non-conductive processes (or non-vertical conduction), and thus obtain an upper limit to the heat flux 
due to these processes. Figure 12a shows $\epsilon_{\mathrm{rms}}$ in degrees and the residual heating rate (heating-rate error) in $\mathrm{W} \mathrm{m}^{-3}$ as functions of depth for all periods of no sunlight and all thermistor groups; Figure $12 \mathrm{~b}$ shows the relative error $\epsilon_{\mathrm{rms}} / \Delta T_{\mathrm{rms}}$ (Equations (7) and (8)). The cases in which the top thermistor was within $3 \mathrm{~mm}$ of the snow surface are omitted from Figure 12. For those cases, aliasing at the sample interval of $15 \mathrm{~min}$ is likely and indeed they exhibit the largest errors. Below $60 \mathrm{~cm}$ the heating-rate error is less than $0.2 \mathrm{~W} \mathrm{~m}^{-3}$ and the relative error is less than $8 \%$, indicating that vertical conduction explains $92 \%$ of the heat flux.

\section{ESTIMATION OF NON-CONDUCTIVE HEAT FLUX}

We did not investigate heating rates due to solar radiation when the sun was up, because of an experimental difficulty also experienced by Trowbridge (1993). Even though we minimized selective radiative heating of thermistors by covering them with mylar shields, the thermistors registered
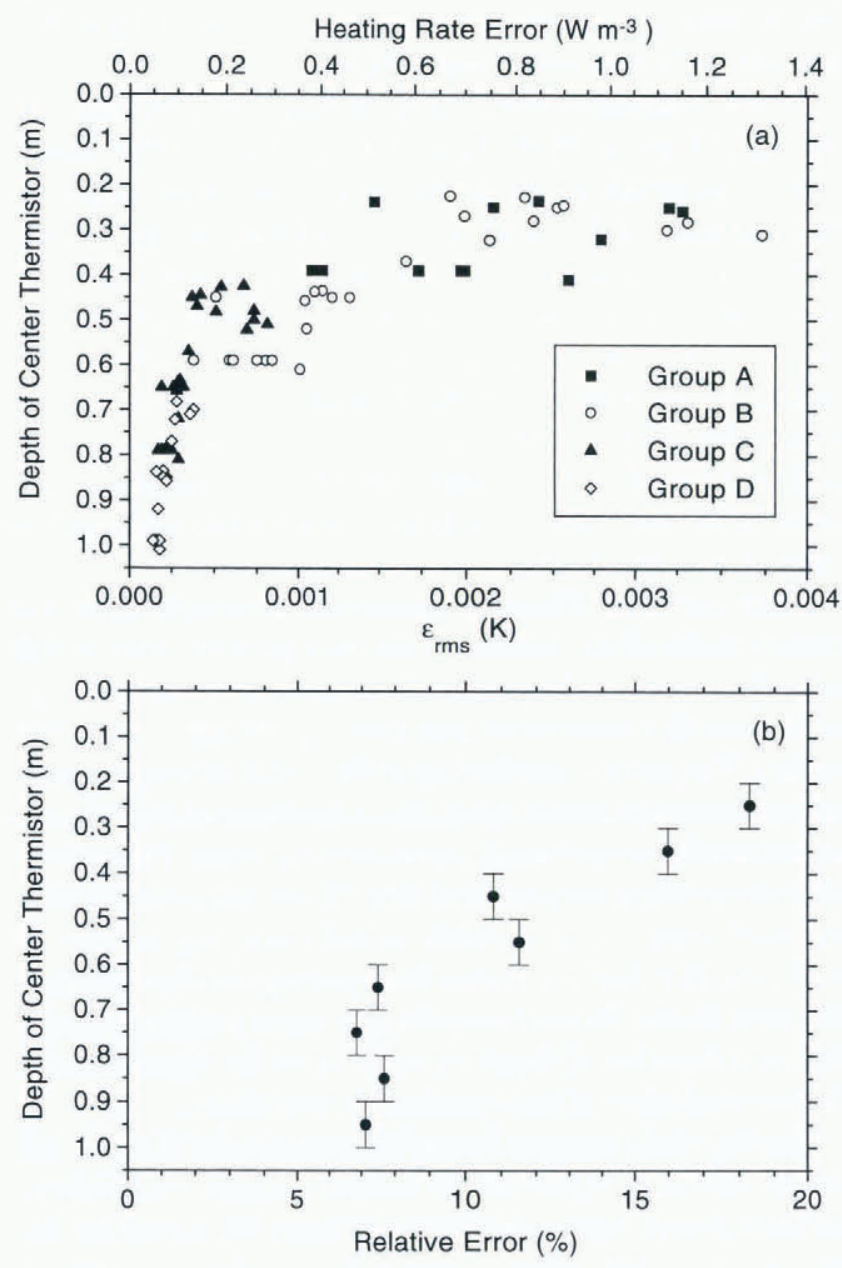

Fig. 12. (a) Root-mean-square error in predicted temperature change, $\epsilon_{\mathrm{rms}}$ (Equation (7)) as a function of depth for all thermistor groups for all periods of no sunlight. The top axis indicates the equivalent residual heating rate. The model uses the average conductivity for each group (horizontal lines in Figure 10). (b) Relative error in predicted temperature change, $\epsilon_{\mathrm{rms}} / \Delta T_{\mathrm{rms}}$ (Equations (7) and (8)) vs depth, averaged over $10 \mathrm{~cm}$ intervals for all thermistor groups for all periods of no sunlight. The predicted temperature change was computed using the 6 month average conductivity for each group. temperatures up to $0.2 \mathrm{~K}$ higher than the snow temperature. It is difficult to monitor snow temperature in the presence of solar radiation. One can observe the cooling curve after shading the snow to get an instantaneous snow-temperature profile a few seconds after the thermistors have equilibrated to the actual snow temperature (Brandt and Warren, 1993, fig. 7), but this method disrupts the thermal regime and is difficult to implement operationally to track snow temperatures over several months. However, solar radiation is not expected to cause internal heating within the snowpack below the top few centimeters in the case of pure, dry snow at densities found on the Antarctic Plateau Brandt and Warren, 1993).

We now search for a windpumping contribution to the residual heating rates in winter that are not accounted for by vertical conduction. These residual heating rates are significant for the upper thermistor groups $\mathrm{A}$ and $\mathrm{B}$, at shallow depths where windpumping would be expected to have the greatest effect. We therefore seek a windpumping signal in a correlation of the unexplained heating rates in groups $\mathrm{A}$ and $\mathrm{B}$ to meteorological variables from Figure 3, only for cases where the top of the group was less than $20 \mathrm{~cm}$ from the surface. The most probable type of windpumping that would disrupt the thermal regime of the underlying snow on the scale of centimeters to meters would be caused by air flow over undulations, which at the South Pole would be sastrugi Colbeck, 1989; Cunningham and Waddington, 1993). The perturbation pressure $P$, and hence the vertical air-flux volume of this type of windpumping, is proportional to the square of the wind speed $U$ (Colbeck, 1989). In addition, the disruption of the snow's thermal regime due to windpumping should be proportional to the temperature difference between air and snow $\left(T_{\mathrm{a}}-T_{\mathrm{m}}\right)$. We define the unexplained temperature change $\epsilon$ for a particular time step as $\epsilon=\Delta T_{\mathrm{m}}-\Delta T_{\mathrm{c}}$ (cf. Equation (7)), and correlate $\epsilon(t)$ with $U^{2}\left(T_{\mathrm{a}}-T_{\mathrm{m}}\right)$, using the hourly values of wind speed (which were shown smoothed in Figure 3) and only the data-collection periods during the polar night so as not to involve solar radiation. As shown in Table 1 and Figure 13a and $\mathrm{b}$, this correlation explains $21 \%$ of the residual heating, or $3.1 \%$ of the total heating. However, this correlation does not by itself identify windpumping as the cause of the unexplained temperature changes, because non-vertical conduction is also proportional to $T_{\mathrm{a}}-T_{\mathrm{m}}$. We therefore also show

Table 1. Correlation of unexplained temperature change $\epsilon \equiv\left(\Delta T_{\mathrm{m}}-\Delta T_{\mathrm{c}}\right)$, at $25-40 \mathrm{~cm}$ depth with various meteorological parameters. Correlation coefficient is $r ; r^{2}$ is the fraction of variance accounted for by the parameter. $F_{\mathrm{p}}$ indicates the per cent of the total temperature change accounted for by the parameter. The correlations of $\epsilon$ with $U^{2}\left(T_{\mathrm{a}}-T_{\mathrm{m}}\right),\left(T_{\mathrm{a}}-T_{\mathrm{m}}\right)$ and $U^{2}$ are plotted in Figure 13

\begin{tabular}{lll}
\hline \multicolumn{1}{c}{ Parameter } & $r^{2}$ & $F_{\mathrm{p}}$ \\
\hline$U^{-2}\left(T_{\mathrm{a}}-T_{\mathrm{m}}\right)$ & 0.21 & $3.1 \%$ \\
$\left(T_{\mathrm{a}}-T_{\mathrm{m}}\right)$ & 0.32 & $4.7 \%$ \\
$U^{2}$ & 0.03 & $0.4 \%$ \\
$\mid \mathrm{d} P / \mathrm{d} t l\left(T_{\mathrm{n}}-T_{\mathrm{m}}\right)$ & 0.19 & $2.8 \%$ \\
$|\mathrm{~d} P / \mathrm{d} t|$ & 0.0004 & $0.01 \%$
\end{tabular}

Symbols: $U$, wind speed; $T_{\mathrm{a}}$, air temperature; $T_{\mathrm{m}}$, measured snow temperature; $\Delta T_{c}$, calculated change in snow temperature; $P$, air pressure; $t$, time. 

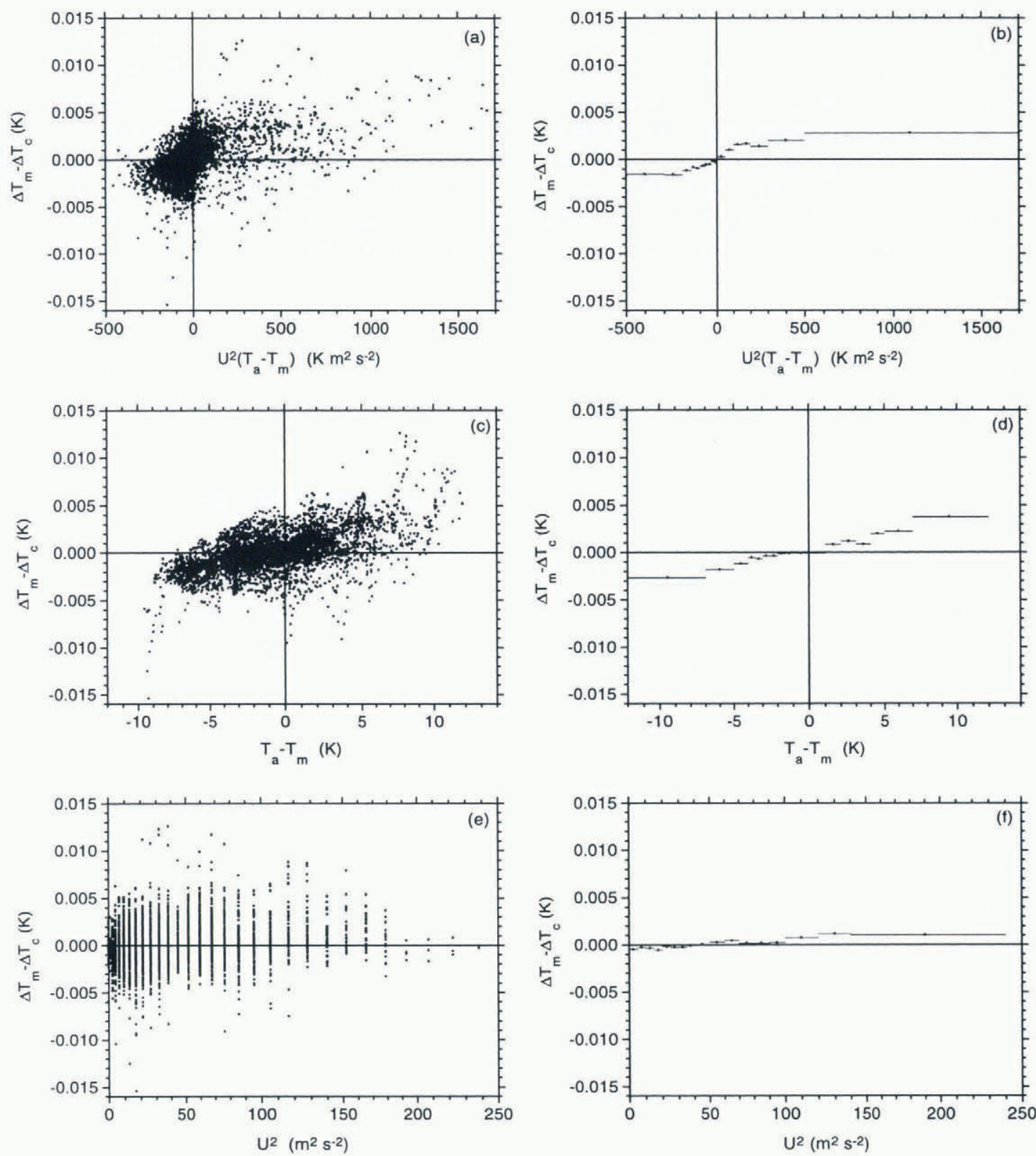

Fig. 13. Error in model-predicted temperature change, plotted against a parameter that should be proportional to heating rate by windpumping, $U^{2}\left(T_{\mathrm{a}}-T_{\mathrm{m}}\right)$, as well as $\left(T_{\mathrm{a}}-T_{\mathrm{m}}\right)$ and $U^{2}$ separately, where $U$ is $10 \mathrm{~m}$ wind speed, $T_{\mathrm{a}}$ is $2 \mathrm{~m}$ air temperature and $T_{\mathrm{m}}$ is measured temperature at the center thermistor group of a three-thermistor group. Each point in $(a),(c)$ and $(e)$ represents a single thermistor group for a single $15 \mathrm{~min}$ interval. Sunlit times as well as the initial $30 \mathrm{~h}$ of each $9 \mathrm{~d}$ period are excluded. A total of 5122 points is plotted in each of the lefthand frames. The nature of the correlation is more easily observed by forming groups of data points. The horizontal axes are therefore divded into bins containing approximately equal numbers of data points and the averages for these bins are plotted on the righthand frames.

the correlations of $\epsilon$ with $T_{\mathrm{a}}-T_{\mathrm{m}}$ and $U^{2}$ separately. Table 1 and Figure $13 \mathrm{c}$ and $\mathrm{d}$ show that $\left(T_{\mathrm{a}}-T_{\mathrm{m}}\right)$ alone explains more of $\epsilon$ than does $U^{2}\left(T_{\mathrm{a}}-T_{\mathrm{m}}\right)$. $U^{2}$ is essentially uncorrelated with $\epsilon$ as shown in Figure 13e and $f$. We also tried corrclating $\epsilon$ with another possible measure of windpumping, $|\Delta p|\left(T_{\mathrm{a}}-T_{\mathrm{m}}\right)$, where $\Delta p$ is the change in barometric pressure, and again did not find significant correlation (Table 1). Convection within the snowpack would correlate with $\left(T_{\mathrm{a}}-T_{\mathrm{m}}\right)$ but it is unlikely to contribute much to the heat flux because of the high snow density. Non-vertical heat conduction could be responsible for correlation between $\left(T_{\mathrm{a}}-T_{\mathrm{m}}\right)$ and the one-dimensional model's residual heating error $\epsilon$, especially when a vertical wall of a sastruga was close to the thermistor string as was sometimes observed. The fact that the correlation of $\epsilon$ with $U^{2}\left(T_{\mathrm{a}}-T_{\mathrm{m}}\right)$ was less than that with $\left(T_{\mathrm{a}}-T_{\mathrm{m}}\right)$ suggests that the small residual heating $\epsilon$ is mostly due to non-vertical conduction and to vertical variability in $k_{\text {eff }}$ rather than to windpumping.

\section{DISCUSSION}

Comparing Figures 7 and 12, we see that for example at $50 \mathrm{~cm}$ depth, changes of up to $0.03 \mathrm{~K}$ in a $15 \mathrm{~min}$ time step can be explained to within $0.001 \mathrm{~K}$ by vertical conduction alone. We did not observe rapid temperature changes due to windpumping such as have been reported by Albert and McGilvary (1992) and Albert and Hardy (1995). In laboratory and in situ forced-air experiments, they found temperature changes of up to $1 \mathrm{~K}$ at $20 \mathrm{~cm}$ depth, whereas our maximum temperature change at $20 \mathrm{~cm}$ was only $0.1 \mathrm{~K}$ (Fig. 7). However, the snow they studied was low-density 
seasonal snow $\left(150 \mathrm{~kg} \mathrm{~m}^{-3}\right)$, with a permeability nearly 20 times that of typical snow on the Antarctic Plateau, which is at least twice as dense. This difference in snow type is probably sufficient to explain why our experiment had a different outcome than theirs, although differences in thermal conductivity and local temperature gradients may also be significant. Albert (1995) developed a finite-element heat-transfer model which agreed with her experimental results, and which also suggests that slow advection could be occurring in South Polar snow without significantly affecting measured temperatures.

The theoretical and experimental evidence of the depth to which windpumping occurs on an ice sheet is limited. Clarke and Waddington (1991) improved their windpumping model to consider three-dimensional air flow and found that the depth to which windpumping occurs in one-dimensional models is overestimated. Waddington (personal communication) expects most of the air flow for a "sastrugied" snow surface to occur to a depth comparable to the height of the sastrugi, which in our case varied from 0 to $30 \mathrm{~cm}$. Colbeck (1993) pointed out that the heat capacity of snow (of density $\rho=500 \mathrm{~kg} \mathrm{~m}^{-3}$ ) is 850 times that of air. Thermal signatures of windpumping might then be subtle and lowvelocity windpumping may occur without significantly disrupting the snow's thermal regime. Even if windpumping does not significantly affect snow temperatures on the Antarctic Plateau, it can still be important for aerosol deposition, which occurs only in the top few centimeters (Albert, 1996; Harder and others, 1996).

Albert and others (1996) measured the vertical snow permeability at Summit, Greenland; it increased from $3 \times 10^{-10} \mathrm{~m}^{2}$ at the surface to $28 \times 10^{-10} \mathrm{~m}^{2}$ at $1 \mathrm{~m}$ depth. They also showed that the horizontal permeability could be a factor of 2 larger than the vertical permeability. This is probably true in Antarctica as well, because the vertical permeability at the South Pole is largely limited by a thin surface crust about $5 \mathrm{~mm}$ thick that forms in late summer (Gow, 1965). The preliminary analysis of Albert and others (1996) shows that the top meter of firn is sufficiently permeable to allow ventilation. It has been shown in one-dimensional calculations (Albert and McGilvary, 1992) and twodimensional calculations (Albert, 1993) that significant air flow can exist in the firn that would not be evident from the temperature profile when the snow has relatively high thermal conductivity, or when there are relatively strong overall temperature gradients. The vertical permeability we measured in the top $10 \mathrm{~cm}$ of South Polar snow, $4 \times 10^{-10} \mathrm{~m}^{2}$, agrees with the Greenland surface value, suggesting that an experiment in Greenland similar to ours might yield similar results.

\section{CONCLUSIONS}

Measurement of snow temperature at South Pole Station during the winter night can be used to estimate the thermal conductivity and to assess the contribution of windpumping to the snow's thermal regime, without the added complexities of solar radiation and transport of latent heat.

Above $40 \mathrm{~cm}$ depth, the estimated snow conductivity is much lower than that given by the parameterizations of Anderson (1976) and Yen (1981) which are functions only of density. We speculate that the low conductivities we observed are due to weak intergranular contacts within the freshly fallen, very cold, winter snow at the South Pole.

Below a depth of $\sim 3 \mathrm{~mm}$, the thermal regime of nearsurface snow at South Pole Station changes slowly enough to be sampled at $15 \mathrm{~min}$ time steps and to be modeled using finite differences in one dimension. Thermal conduction in the vertical direction is responsible for at least $92 \%$ of the heat flux below a depth of $60 \mathrm{~cm}$ (3-4 annual layers). Our model's heating-rate error is less than $0.2 \mathrm{Wm}^{-3}$ at $65 \mathrm{~cm}$ depth. The residual heat flux at shallower depths is partly attributable to non-vertical conduction or variability of $k_{\text {eff }}$ within each modeled region. We failed to find evidence that windpumping causes significant heat flux below $20 \mathrm{~cm}$ depth; its effects on the thermal regime may be confined to snow nearer the surface.

\section{ACKNOWLEDGEMENTS}

We thank O. Brandt, E. Waddington and B. Hallet for useful discussions, P. Mazure and R. Spain of Antarctic Support Associates for instrument deployment, D. Morse for the permeability measurements and D. Worthen and R. Boime for assistance in the field. We also thank M. Sturm, M. Albert, T. Arons and K. Cuffey for reviewing the manuscript. The research was supported by U.S. National Science Foundation grants DPP-88-18570, OPP-91-20380 and OPP-9421096.

\section{REFERENCES}

Abels, G. 1892. Beobachtungen der täglichen Periode der Temperatur im Schnee und Bestimmung des Wärmeleitungsvermögens des Schnees als Funktion seiner Dichtigkeit. Kaiserliche Akademie der Wissenschaften. Repertorium für Meleorologie, 16 (1), 1-53.

Adams, E. E. and A. Sato. 1993. Model for effective thermal conductivity of a dry snow cover composed of uniform ice spheres. Ann. Glaciol., 18, 300304.

Albert, M. R. 1993. Some numerical experiments on firn ventilation with heat transfer. Ann. Gilaciol., 18, 161-16.5.

Albert, M. R. 1995. Advective diffusive heat transfer in snow. In ASME International Mechanical Engineering Congress and Exposition, 1217 November 1995, San Franciso, CA. New York, American Society of Mechanical Engineers, 1-4 (Pub. 95-WA/HT-44.)

Albert, M. R. 1996. Modeling heat, mass, and species transport in polar firn. Ann. Glaciol., 23, 138-143.

Albert, M. R. and J. P. Hardy. 1995. Ventilation experiments in a seasonal snow cover. International Association of Hydrological Sciences Publication 228 Symposium at Boulder 1995 - Biogeochemistry of Seasonally Snow-Covered Catchments), 41-49.

Albert, M. R. and W. R. McGilvary: 1992. Thermal effects due to air flow and vapor transport in dry snow. F. Glaciol., 38 129), 273-281.

Albert, M. R., E. M. Arons and R. E. Davis. 1996. Firn properties affecting gas exchange at Summit, Greenland: ventilation possibilities. In Wolff, E.W. and R. C. Bales, eds. Chemical exchange between the atmosphere and polar snow. Berlin, etc., Springer-Verlag, 561-565. (NATO ASI Series I: Global Environmental Change 43.

Anderson, E. A. 1976. A point energy and mass balance model of a snow cover. NOAA Tech. Rep. NWS-19.

Arons, E. M. and S. C. Colbeck. 1995. Geometry of heat and mass transfer in dry snow: a review of theory and experiment. Rev. Geoplys., 33 (4), $463-493$.

Bintanja, R. and M. R. van den Broeke. 1995. The surface energy balance of Antarctic snow and blue ice. F. Appl. Meteorol., 34 (4), 902-926.

Brandt, R. E. and S. G. Warren. 1993. Solar-heating and temperature profiles in Antarctic snow and ice. J. Glaciol., 39 (131), 99-110.

Brandt, R. E., T. C. Grenfell and S. G. Warren. 1991. Optical properties of snow. Antarct. F. U.S., 26 (5), 272-275.

Clarke, G. K. C. and E. D. Waddington, 1991. A three-dimensional theory of wind pumping. F. Glaciol., 37 (125), 8996.

Clarke, G. K. C., D. A. Fisher and E. D. Waddington. 1987. Wind pumping: a potentially significant heat source in ice sheets. International Association of Hydrological Sciences Publication 170 (Symposium at Vancouver 1987 - 
The Physical Basis of Ice Sheet Modelling), 169-180.

Colbeck, S. C. 1989. Air movement in snow due to windpumping. J. Glaciol., $35(120), 209-213$.

Colbeck, S. C. 1993. Shifts in ice sheet temperatures. J. Geophys. Res., 98 (D3), 51155120.

Cufley, K. M., G. D. Clow, R. B. Alley, M. Stuiver, E. D. Waddington and R.W. Saltus. 1995. Large Arctic temperature change at the Wisconsin Holocene glacial transition. Science, 270 (5235), 455-458.

Cunningham, J. and E. D. Waddington. 1993. Air flow and dry deposition of non-sea salt sulfate in polar firn: paleoclimatic implications. Atmos. Environ., 27A 17-18), $2943-2956$.

Dalrymple, P. C. 1966. A physical climatology of the Antarctic Plateau. In Rubin, M.J., ed. Studies in Antartic meteorolog): Washington, DC, American Geophysical Union, 195 -231. (Antarctic Research Series 9.

Dalrymple, P. C., H. H. Lettau and S. H. Wollaston. 1966. South Pole micrometeorology program: data analysis. In Rubin, M.J., ed. Studies in Antare(if meteorolog): Washington, DC, American Geophysical Union, 13-57. (Antarctic Research Series 9.

Gow, A.J. 1965. On the accumulation and seasonal stratification of snow at the South Pole. J. Glaciol., 5 40, 467-477.

Grenfell, T. C., S. G. Warren and P. C. Mullen. 1994. Reflection of solar radiation by the Antarctic snow surface at ultraviolet, visible, and near-infrared wavelengths. f. Geophys. Res., 99 (D9), 18,669-18,684.

Harder, S. L., S. G. Warren, R. J. Charlson and D. S. Covert. 1996. Filtering of air through snow as a mechanism for aerosol deposition to the Antarctic ice sheet. J. Geophys. Res., 101 (D13), 18,729-18,743.

Hjeltström, S.A. 1889. Sur la conductibilité de la neige. Ofversigt af Kongl. Vetenskaps-Akademiens Forhandlinger, 46 10), 669-676.

LaChapelle, E. R. 1969. Field guide to snow crystals. Seattle, WA, University of Washington Press.

Lange, M. A. 1985. Measurements of thermal parameters in Antarctic snow and firn. Ann. Glaciol., 6, 100-104.

Lettau, B. 1967. Sub-surface heat flux in the Antarctic interior. In Polar Meteorolog). Geneva, World Meteorological Organisation, 175188. (WMO Tech. Note 87, WMO-211.
Mellor, M. 1977. Engineering properties of snow: f. Glaciol., 19 81), 15-66. Press, W. H., B. P. Flannery, S. A. Teukolsky and W.T. Vetterling. 1992. Nimerical recipes in FORTRA.N: the art of scientific computing. Second edition. Cambridge, Cambridge University Press.

Schaaf, J.W. and D. Williams. 1973. Optical constants of ice in the infrared. j. Opt. Soc. Am., $636,726-732$.

Schwerdtfeger, W. 1970. The climate of the Antarctic. In Orvig, S., ed. Climates of the polar regions. New York, Elsevier, 253-355.

Schwerdtfeger, W. 1977. Temperature regime of the South Pole: results of 20 years' observations at Amundsen Scott Station. Antart. F. U.S., 12 4), $156-159$.

Sturm, M. and J. B. Johnson. 1992. Thermal conductivity measurements of depth hoar. f. Geophys. Res., 97 (B2), 21292139.

Sturm, M., J. Holmgren, M. König and K. Morris. 1997. The thermal conductivity of seasonal snow. f. Glaciol., 43 (143), $26-41$.

Trowbridge, P. 1993. The effect of windpumping on the thermal regime of the upper firn at Taylor Dome, Antarctica. (B.Sc. thesis, University of Washington. Department of Geological Sciences.

Turcotte, D. L. and G. Schubert. 1982. Geodynamics: applications of contimuum physics to geological problems. New York, etc., John Wiley and Sons.

Waddington, E. D. and D. L. Morse. 1994. Spatial variations of local climate at Taylor Dome, Antarctica: implications for paleoclimate from ice cores. Ann. Glaciol., 20, $219-225$.

Warren, S. G. 1984. Optical constants of ice from the ultraviolet to the microwave. Appl. Opt., 23 (8), 12061225.

Weller, G. and P. Schwerdtfeger. 1977. Thermal properties and heat transfer processes of low-temperature snow. In Businger, J. A., ed. Meteorological studies at Plateau Station, Antarctica. Washington, DC, American Geophysical Union, 27-34. (Antarctic Research Series 25.

Wexler, H. 1958. The "kernlose" winter in Antarctica. Geophysica, 6 3), 577-595.

Yen, Y. -C. 1981. Review of thermal properties of snow, ice and sea ice. CRREL Rep. 81-10.

Zhang, T. and T. E. Osterkamp. 1995. Considerations in determining thermal diffusivity from temperature time series using finite difference methods. Cold Reg. Sci. Technol., 23 4),333-341. 